\title{
Uji kekuatan bending pipa komposit jute-epoxy pada perlakuan rendaman air panas
}

\author{
I Wayan Purna Wirama1), I Made Astika1), I.D.G. Ary Subagia ${ }^{1}{ }^{\star}$, \\ ${ }^{1)}$ Teknik Mesin Fakultas Teknik Universitas Udayana, Kampus Bukit Jimbaran, Badung (80362), Bali.
}

\author{
Naskah diterima 20/06/2021; direvisi 24/09/2021; disetujui 30/09/2021
}

doi: https://doi.org/10.24843/JEM.2021.v14.i02.p07

\begin{abstract}
Abstrak
Tujuan utama dari penelitian ini adalah untuk mengetahui perbandingan kekuatan bending dari pipa komposit ketika diberi perlakuan air panas. Pada penelitian ini pipa komposit dibuat menggunakan penguat anyaman karung goni dan diikat dengan matrik epoxy yang dicetak dengan metode VARTM (Vacuum Assisted Resin Transfer Molding). Komposit laminasi serat jute pada pengikat epoxy dibuat dengan laminasi 3 lapisan dengan arah serat $45^{\circ}$ dan memiliki tebal 2 , $55 \mathrm{~mm}$, pipa komposit jute-epoxy akan diberi perlakuan Temperatur panas. Lalu di uji pada pembebanan bending. Hasil dari penelitian ini tegangan dan regangan bending pada spesimen kontrol dibandingkan dengan spesimen perlakuan panas, terjadiya peningkatan regangan terhadap spesimen perlakuan panas sebesar 0,007 [MPa], hal ini diakibatkan adanya treatmen temperature panas pada spesimen yang menyebabkan perubahan sifat dari spesimen itu sendiri, yang awalnya spesimen bersifat getas berubah menjadi plastis. Sedangkan pada nilai tegangan bending dan modulus elastisitas pada spesimen kontrol dan spesimen perlakuan panas. Diperoleh tegangan pada pipa komposit kontrol yaitu sebesar 67,946 [MPa] dengan modulus elastisitas sebesar 10,398 [GPa]. Sedangkan pipa komposit yang diberi perlakuan panas memiliki sifat tegangan bending sebesar 28,613 [MPa] dengan modulus elastisitas sebesar $2,225[\mathrm{GPa}]$.
\end{abstract}

Kata kunci: Pipa komposit, anyaman jute, resin epoxy, VARTM, uji bending.

\begin{abstract}
The main purpose of this study was to determine the comparison of the bending strength of composite pipes when treated with hot water. In this study, composite pipes were made using woven sacks and tied with an epoxy matrix which was molded using the VARTM (Vacuum Assisted Resin Transfer Molding) method. Jute fiber laminated composite on epoxy binder is made by laminated 3 layers with fiber direction $45^{\circ}$ and has a thickness of $2.55 \mathrm{~mm}$, the jute-epoxy composite pipe will be treated with heat treatment. Then tested on bending loading. The results of this study were the bending stress and strain on the control specimen compared to the heat treated specimen, an increase in the strain of the heat treatment specimen was 0.007 [MPa], this was due to the heat treatment temperature on the specimen which caused a change in the properties of the specimen itself, which was initially a brittle specimen changes to plastic. Meanwhile, the value of bending stress and modulus of elasticity on control specimens and heat treatment specimens. The obtained stress on the control composite pipe is 67.946 [MPa] with a modulus of elasticity of 10.398 [GPa]. While the heat-treated composite pipe has a bending stress of 28.613 [MPa] with an elastic modulus of 2.225 [GPa].
\end{abstract}

Keywords: Composite pipe, jute woven, epoxy resin, VARTM, bending test.

\section{Pendahuluan}

Pipa adalah saluran dengan penampang lingkaran yang digunakan untuk mengalirkan fluida cair maupun gas [1]. Selain itu, pipa dipergunakan untuk mengalirkan fluida non-kimia atau kimia. Pipa terbuat dari material logam yang kuat dan memiliki daya tahan yang tinggi terhadap perubahan cuaca. Namun kekurangan dari pipa berbahan logam yaitu memiliki bobot yang berat, tidak tahan korosi, dan membutuhkan proses pengelasan saat penyambungan [2].

Sebagai upaya pengendalian kelemahan pipa logam, pipa berbahan dasar Polyvinyl chloride (PVC) dan pipa polyethylene (PE) telah dikembangan [3]. Keunggulan dari pipa berbahan PVC dan PE adalah tahan lama, non-degradable, ramah lingkungan, mudah dalam instalasi, tahan korosi dan abrasi, tahan benturan tinggi (Impact Strength), tahan terhadap hampir semua alkalin atau zat beracun bebas pemeliharaan, renewable, dan ekonomis [4]. Selain keunggulan yang telah disebutkan, kekurangan utama dari pipa berbahan dasar PVC adalah tidak tahan terhadap perubahan temperatur tinggi oleh karena itu bahan alami mulai dimanfaatkan sebagai bahan dasar pipa komposit [5]. Tujuan dari pengembangan material komposit saat ini adalah untuk menciptakan material yang ringan, sifat mekanik yang unggul, tahan terhadap korosi dan perlakuan kimia, serta murah. Di samping itu bersifat ramah lingkungan [6].

\section{Metode Penelitian}

\subsection{Bahan Komposit}


Gambar 1a dan 1b menunjukkan bahan penguat dan pengikat dari pipa komposit. Penguat yang digunakan adalah serat jute yang dianyam sederhana. Kemudian, matrik yang digunakan adalah epoxy EPR 174 dan hardener EPH 555. Karakteristik dari anyaman jute dan epoxy ditunjukkan pada Tabel 1, 2, 3.

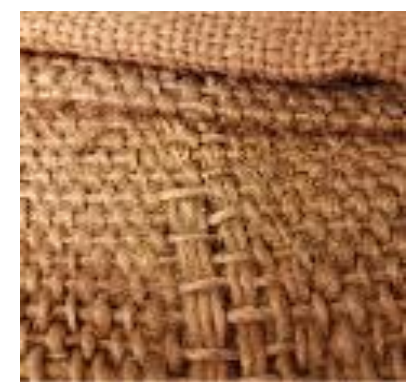

(a)

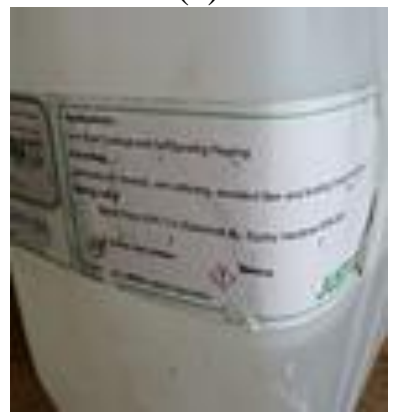

(b)

Gambar 1. (a) Anyaman Jute, (b) Resin Epoxy.

2.2. Sifat dan Karakteristik Bahan

Tabel 1. Komposisi serat jute [7]

\begin{tabular}{lc}
\hline \multicolumn{1}{c}{ Category/Unit } & Standard \\
\hline Selulosa & $71 \%$ \\
Lignin & $13 \%$ \\
Hemiselulosa & $13 \%$ \\
Pektin & $0.20 \%$ \\
Zat-zat lain yang larut & $2.30 \%$ \\
dalam air & $0.50 \%$ \\
\hline
\end{tabular}

Tabel 2. Sifat mekanis serat jute tanpa perlakuan

\begin{tabular}{lc}
\hline \multicolumn{1}{c}{ Category/Unit } & Standard \\
\hline Diameter serat $(\mu \mathrm{m})$ & 26 \\
Panjang serat $(\mathrm{mm})$ & 5 -Jan \\
Kehalusan (denier) & $3-7$ \\
Berat jenis $(\mathrm{g} / \mathrm{cm} 3)$ & $1.5-1.6$ \\
Mulur $(\%)$ & 1.7 \\
Fracture load $(\mathrm{N})$ & 0.467
\end{tabular}

Tensile strength (MPa) 1316

Fracture strain (\%) $\quad 0.025$

Young's Modulus (Gpa) $\quad 91.9$

Tabel 3. Karakteristik epoxy resin EPR-174

\begin{tabular}{lc}
\hline \multicolumn{1}{c}{ Category/Unit } & Standard \\
\hline $\begin{array}{l}\text { Density at } 25^{\circ} \mathrm{C} \\
(\mathrm{g} / \mathrm{cm} 3)\end{array}$ & $1.16 \pm 0.02$ \\
Hardener type & $\begin{array}{c}\text { Cyclonliphatic } \\
\text { Amine (EPH-555) }\end{array}$ \\
$\begin{array}{l}\text { Epoxy resin type } \\
\text { Bisphenol A- } \\
\text { Epichlorohydrin }\end{array}$ \\
$\begin{array}{l}\text { Tensile strength (MPa) } \\
\begin{array}{l}\text { Compressive strength } \\
\text { (MPa) }\end{array}\end{array}$ & 63.7 \\
$\begin{array}{l}\text { Flexural strength } \\
\text { (MPa) }\end{array}$ & 88.2 \\
\hline
\end{tabular}

2.3. Desain dan Proses Manufaktur Pipa

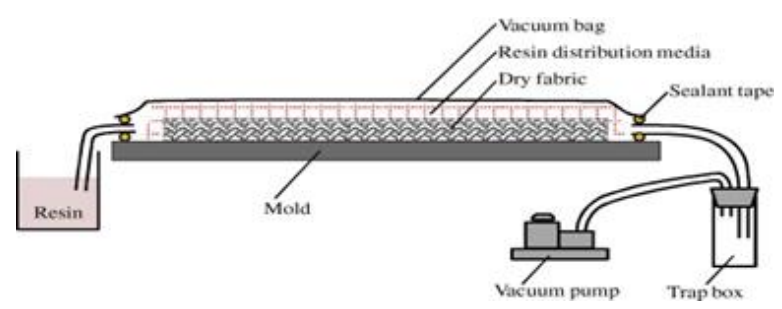

Gambar 2. Skema proses manufaktur spesimen komposit dengan metode VARTM.

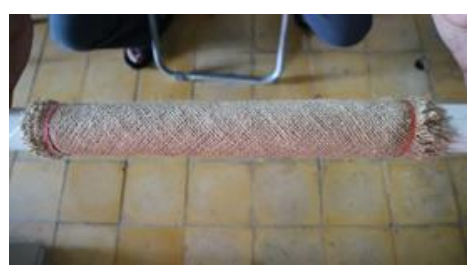

(a)

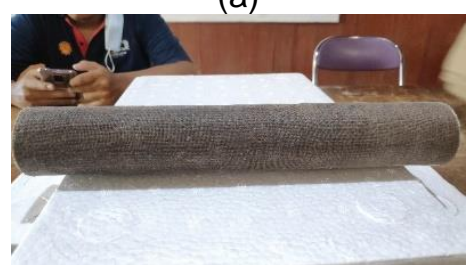

(b)

Gambar 3. (a) Metode laminasi anyaman jute $45^{\circ}$ pada pipa cetakan komposit, (b) Hasil cetakan pipa komposit

\subsection{Pengujian Bending Pipa}

Morpologi patahan komposit CU/epoksi Kekuatan bending atau kekuatan lengkung adalah tegangan bending terbesar yang dapat diterima akibat pembebanan luar tanpa mengalami 
deformasi yang besar atau kegagalan.[8] Besar kekuatan bending tergantung pada jenis material dan pembebanan. Akibat pengujian bending,[9] bagian atas spesimen mengalami tekanan, sedangkan bagian bawah akan mengalami tegangan tarik. Dalam material komposit, kekuatan tekannya lebih tinggi daripada pada kekuatan tariknya.[10],[8] Karena tidak mampu menahan tegangan tarik yang diterima, spesimen tersebut akan patah, hal tersebut mengakibatkan kegagalan pada pengujian komposit.[11] Kekuatan bending pada sisi bagian atas sama nilai dengan kekuatan bending pada sisi bagian bawah.[10].

Dalam pengujian bending ada yang dikenal dengan istilah Point bending. Point bending berfungsi sebagai tumpuan benda uji dan juga sebagai penerus gaya tekan yang dikeluarkan oleh alat tekan. Panjang pendek tumpuan point bending berpengaruh terhadap hasil pengujian.[9] Alat ukur adalah suatu alat yang yang menunjukan besarnya kekuatan tekan yang terjadi pada benda uji. Uji bending adalah suatu proses pengujian material dengan cara di tekan untuk mendapatkan hasil berupa data tentang kekuatan lengkung (bending) suatu material yang di uji. [6], [7]. Pada pengujian bending ini menggunakan cara three point bending yaitu cara pengujian bending dengan dua tumpuan dan satu penekan.

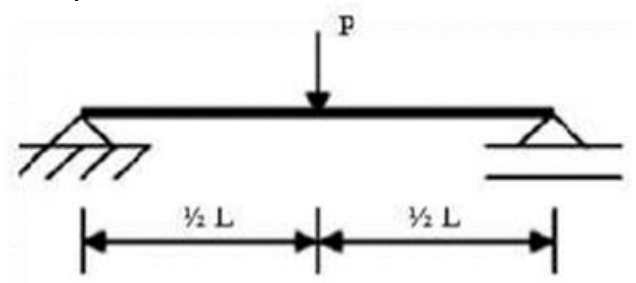

Gambar 4. Three Point Bending

Persamaan yang digunakan yaitu:

$$
\begin{array}{ll}
\mathrm{M} & =\frac{(F \cdot L)}{4} \\
\mathrm{Z} & =\frac{\pi\left(D_{0}{ }^{3}-D i^{3}\right)}{32} \\
\text { Bending Stress } & =\frac{M}{Z}=\frac{(8 \cdot F \cdot L)}{\pi\left(D_{0}^{3}-D i^{3}\right)} \\
\mathrm{I} & =\frac{\pi\left(D_{0}{ }^{4}-D i^{4}\right)}{64} \\
\text { Strain } & =\frac{\left(6 \cdot\left(D_{0}-D i\right) \cdot D L\right)}{\left(L^{2}\right)}
\end{array}
$$

Keterangan:

$$
\begin{array}{ll}
\mathrm{M} & =\text { Momen Bending }(\mathrm{Ncm}) \\
\mathrm{F} & =\text { Besar Beban }(\mathrm{N}) \\
\mathrm{L} & =\text { Jarak Tumpuan }(\mathrm{cm}) \\
\mathrm{Z} & =\text { Rectangular Section Modulus }\left(\mathrm{cm}^{3}\right) \\
\mathrm{D}_{\mathrm{o}} & =\text { Diameter Luar Spesimen }(\mathrm{cm}) \\
\mathrm{D}_{\mathrm{i}} & =\text { Diameter Dalam Spesimen }(\mathrm{cm})
\end{array}
$$

I = Rectangular Moment of Inertia

$\left(\mathrm{cm}^{4}\right)$

Strain = Regangan

$\mathrm{DL} \quad=$ Deflection in Bending

\section{Hasil dan Pembahasan}

3.1. Data Spesimen

Ukuran spesimen uji bending mengikuti standar uji ASTM D2166M-16, ukurannya yaitu:

$$
\begin{array}{ll}
\mathrm{L} & =300 \mathrm{~mm} \\
\mathrm{Do} & =48 \mathrm{~mm} \\
\mathrm{Di} & =43 \mathrm{~mm}
\end{array}
$$

\subsection{Data Hasil Uji Bending}

Tabel 4. Data Uji bending

\begin{tabular}{cccc}
\hline $\begin{array}{c}\text { Nama } \\
\text { Spesimen }\end{array}$ & $\begin{array}{c}\sigma \\
\text { (Mpa) }\end{array}$ & $\begin{array}{c}\boldsymbol{\varepsilon} \\
(\mathbf{m m} / \mathbf{m m})\end{array}$ & $\begin{array}{c}\mathrm{E} \\
\text { (Gpa) }\end{array}$ \\
\hline $\begin{array}{c}\text { Spesimen } \\
\text { Kontrol } \\
\begin{array}{c}\text { Spesimen } \\
\text { Perlakuan } \\
\text { Panas }\end{array}\end{array}$ & 67,946 & 0,007 & 10,398 \\
\hline
\end{tabular}

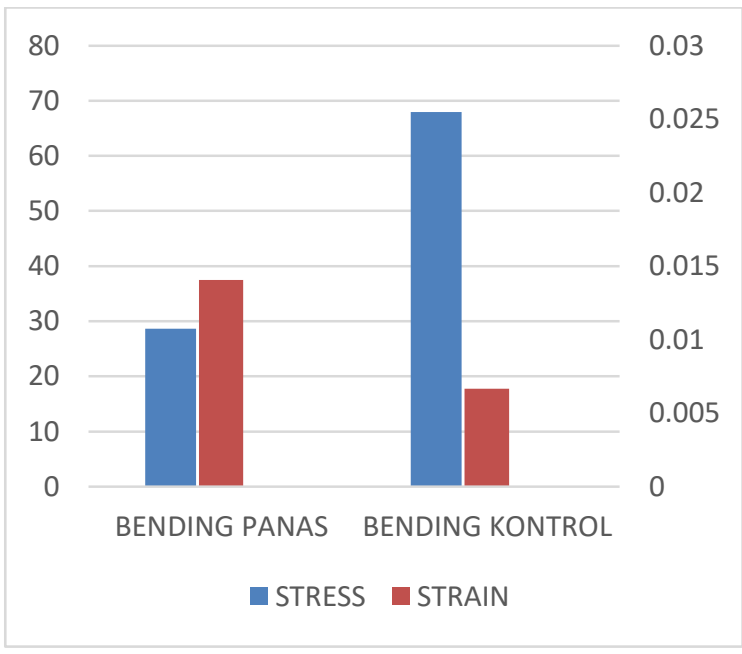

Gambar 5. Grafik hubungan tegangan dan regangan 


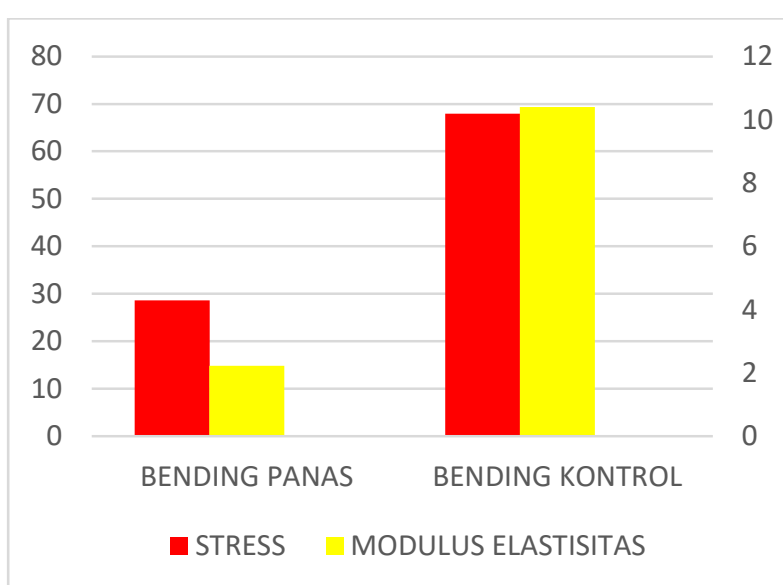

Gambar 6. Grafik hubungan tegangan dan Modulus elastisitas

Pada Gambar 5 menunjukan perbandingan nilai tegangan bending dan regagan pada spesimen kontrol dan spesimen perlakuan panas. Terjadiya peningkatan regangan terhadap spesimen perlakuan panas sebesar $0,007 \mathrm{MPa}$, hal ini diakibatkan adanya treatmen temperature panas pada spesimen yang menyebabkan perubahan sifat dari spesimen itu sendiri, yang awalnya spesimen bersifat getas berubah menjadi plastis.

Pada Gambar 6 menunjukkan perbandingan nilai tegangan bending dan modulus elastisitas pada spesimen kontrol dan spesimen perlakuan panas. Diperoleh tegangan pada pipa komposit kontrol yaitu sebesar $67,946 \mathrm{MPa}$ dengan modulus elastisitas sebesar 10,398 GPa. Sedangkan pipa komposit yang diberi perlakuan panas memiliki sifat tegangan bending sebesar $28,613 \mathrm{MPa}$ dengan modulus elastisitas sebesar 2,225 GPa.

\section{Simpulan}

Berdasarkan dari seluruh tahapan penelitian yang sudah dilakukan maka ditarik kesimpulan bahwa dengan memberikan perlakuan panas pada spesimen komposit Jute-epoxy mengakibatkan turunya nilai tegangan bending pada setiap spesimen yang diberi perlakuan panas namun nilai regangan bending meningkat.

Hasil rata-rata yang didapatkan dari ketiga spesimen kontrol yaitu nilai tegangan bending sebesar 67,9458 $\mathrm{MPa}$, regangan 0,0066, dan modulus elastisitas sebesar 10,3983 Gpa. Sedangkan pada spesimen dengan perlakuan panas hasil rata-rata yang didapatkan dari ketiga spesimen yaitu nilai tegangan bending sebesar 28,6132 $\mathrm{MPa}$, regangan 0,0140 , dan modulus elastisitas sebesar 2,2247 GPa. Hal ini menunjukan bahwa nilai tegangan bending spesimen kontrol mengalami penurunan sebesar $61 \%$ setelah diberi perlakuan panas.

\section{Daftar Pustaka}

[1] H. Pamungkas, "Analisis Pengaliran Air Dalam Pipa Dengan Berbagai Perubahan
Penampang pada Sauatu Jaringan Pipa," 2011.

[2] E. Effendi, Ngafwan, dan A. D. Anggono, "Analisa Kekuatan Pipa Komposit Serat Batang Pisang Polyester Yang Disusun Dua Lapis Serat 250/-250 Terhadap Pengujian Tarik Dengan Variasi Temperatur Ruang Uji," J. Tek. Mesin Fak. Tek. Univ. Muhammadiyah Surakarta, 2015.

[3] D. Y. Trisandi, Pengaruh Diameter Benang Polietilen Terhadap Kekuatan Thermal Mekanis Pipa Komposit Berbahan Ampas Kopi. 2020.

[4] E. Effendi, "Analisa Parameter Kendali Fabrika Produk Pipa Komposit Terhadap Kekuatan Tarik Menggunakan Metode Taguchi," Skripsi, 2015.

[5] I. Tri Statistianto, "Fabrikasi dan Pengujian tarik Pipa Komposit Berpenguat Serat wol Dengan Adiktif Partikel Montmoriillonite," 2013.

[6] A. Fidelis, T.V.C., Pereira, Gomes, D. A. Silva, dan T. Filho, "The effect of fiber morphology on the tensile strength of natural fibers," J. Mater. Res. Technol., vol. 2, hal. 149-157, 2013.

[7] and A. Ms. Dewi Suliyanthini,Dr. Riza. W. Jonathan MM, Dr Tinuk, "Modification Recycle Jute Fibre Waste For Bullet Proof Vests."

[8] A. Syahrani, A. Sam, dan Chairulnas, "Variasi Arus Terhadap Kekuatan Tarik dan Bending Pada Hasil Pengelasan SM490," J. Mek., vol. 4, no. 2, hal. 393402, 2013.

[9] D. Oroh, Jonathan, "Analisis sifat mekanik material komposit dari serat sabut kelapa," J. Poros Tek. Mesin Unsrat, vol. 1, no. 1, hal. 110, 2013.

[10] H. Wona, K. Boimau, E. U. K. Maliwemu, J. T. Mesin, dan U. N. Cendana, "Pengaruh Variasi Fraksi Volume Serat terhadap Kekuatan Bending dan Impak Komposit Polyester Berpenguat Serat Agave Cantula atau lebih gabungan konstituen yang dan tidak larut dalam satu sama lain . Salah," Lontar J. Tek. Mesin, vol. 02, no. 01, hal. 39-50, 2015.

[11] M. Nuruddin, R. A. Santoso, dan R. A. Hidayati, "Desain Komposisi Bahan Komposit yang Optimal Berbahan Baku Utama Limbah Ampas Serat Tebu (Baggase)," Pros. Semin. Nas. Teknoka, vol. 3, no. 2502, hal. 53, 2018, doi: 10.22236/teknoka.v3i0.2915.

[12] M. S. Makmur, "Pengaruh Struktur Core Fiber Metal Laminates (FML) Untuk Aplikasi Rangka Sayap Pesawat Ultralight," 2020. 


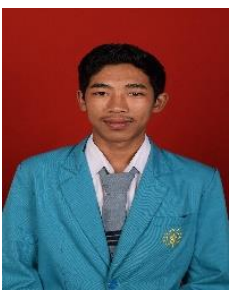

I Wayan Purna Wirama adalah mahasiswa Program Studi Teknik Mesin. Saat ini penulis melakukan penelitian dengan thema kekuatan compressi dari pipa komposit alami.

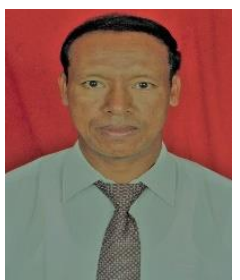

I Made Astika, adalah dosen tetap di Program Studi Teknik Mesin Fakultas Teknik Universitas Udayana. Saat ini menjadi pembimbing dari mahasiswa dengan bidang material komposit. Astika juga secara intent melakukan penelitian terkait dengan karaketristik bahan bahan pembentuk material komposit.

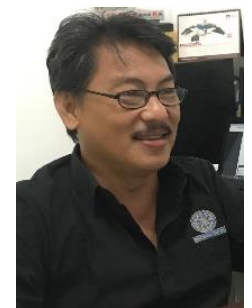

I.D.G. Ary Subagia, adalah dosen tetap di Program Studi Teknik Mesin, Fakultas Teknik Universitas Udayana. Bidang riset yang ditekuni adalah tentang material komposit dengan aplikasi pada konstruksi kendaraan bermotor. Disamping itu, banyak melakukan risetriset terkait struktur dan sifat mekanik dari material komposit. 